\title{
Long Term Patency Rates of Saphenous Vein Grafts a Comparison between Microsurgery and Standard Coronary Bypass Technique
}

\author{
Spagnolo S*, Barbato M, Scalise F, Grasso MA, Spagnolo P and Chierchia SL \\ Department of Cardiovascular, Italy
}

*Corresponding author: Spagnolo S, Department of Cardiovascular, Rapallo (Genoa)

GVM Care \& Research, Italy.

Received Date: August 11, 2018

Published Date: January 17, 2019

\section{Mini Abstract}

To improve patency rates in coronary bypass grafting we borrowed from microsurgery the use of the operating microscope allowing a suturing technique that minimizes anastomosis restriction. When compared to the standard technique, microsurgery afforded considerably greater long term vein grafts patency rates (43 parole).

\section{Abstract}

Background: Approximately $50 \%$ of venous bypass grafts are occluded within 10 years and recent investigations have shown 30 and $40 \%$ occlusion rates respectively 12 and 18 months after the operation. Among the factors accounting for coronary bypass dysfunction and occlusion, defective sutures causing stenosis of the distal anastomosis have been shown to play a relevant role. Based on this consideration, since the early nineties we applied a microsurgical technique to all patients undergoing coronary bypass surgery. In order to evaluate the results obtained with this approach, we compared long term patency rates in two groups of patients who had been previously submitted to coronary bypass grafting by either microsurgery or by the traditional technique.

Result: From January 2000 to December 2008, 388 patients who had been submitted to coronary bypass surgery in our or other institutions underwent repeat coronary angiography at the Policlinico di Monza (Italy). In 239 patients (62\%) CABG had been performed in other hospitals by the "standard" technique while in the 149 patients operated at the Policlinico di Monza (38\%) revascularisation had been completed by the microsurgical approach. Respectively 346 (52\%) of the 666 grafts performed with the "standard" technique and 297 of the 354 (83\%) grafts performed by microsurgery were patent. Regardless of the conduit used, patency rates were invariably greater when microsurgery was employed. However, due to the relatively limited size of the study population, the difference between the to techniques reached statistical significance only when vein grafts were compared. In fact, in the two groups vein grafts patency rates were respectively 38 and $81 \%(\mathrm{p}<0.005)$.

Conclusion: Especially for vein grafts, microsurgery results in significantly greater long term patency rates. Our findings suggest that surgical stenosis induced by inaccurate suturing technique may account for a significant proportion of graft occlusions. This observation bears important clinical implications and suggests that, especially when applied on smaller recipient vessels, distal anastomoses should be performed using microsurgical techniques ( 320 parole).

\section{Introduction}

Coronary artery by pass grafting is not a definitive operation especially when saphenous vein grafts are used. In fact, approximately $50 \%$ of venous conduits are occluded within 10 years and 39\% reintervention rates have been reported within 8 years [1]. More recent investigations, such as the Prague IV [2] and the Prevent IV [3] trials, assessed vein grafts patency rates 12 to 18 months after the index operation and showed that respectively
30 and $40 \%$ of vein grafts were occluded at the time of control angiography. Fifty percent occlusion rates were observed if the bypass operation had been performed "off pump" [2].

The observation that patency rates are significantly greater when arterial conduits are used [4], led to the established belief that the main causes of vein graft occlusion are 1) the arterovenous diameter mismatch at the site of the distal anastomosis 
and 2) the progressive development of vein graft disease caused by the increased pressure and shear forces imposed to the vein by the arterial circulation. In fact, while the difference in lumen diameter between coronary arteries and saphenous veins may be responsible for delayed flow velocity in the venous conduit and cause early thrombosis and occlusion [5], vein graft disease is more likely to cause graft failure in the long term [6].

However, a third and often neglected factor that also plays a relevant role in graft failure, is the presence of significant stenosis at the site of the distal anastomosis caused by inappropriate suturing technique. Obviously, the smaller the grafted vessel, the more difficult is to perform a proper anastomosis and, indeed, the rate of graft occlusion appears to be inversely related to the size of the recipient vessel [7].

This observation, along with the high patency rates observed in microsurgery [8], where the calibre of treated vessels is far smaller than the one of epicardial coronary arteries, led us to hypothesize that one major source of vein graft occlusion is the suturing technique and, since the early nineties, we reintroduced microsurgery in coronary venous by-pass grafting.

In the present article we report the results of a retrospective study that we conducted on a cohort of patients in whom coronary by-pass grafting was performed by microsurgery and were submitted to repeat coronary angiography for a variety of surgical indications. By-pass patency rates were assessed and compared to those observed in a similar group of patients submitted to by pass surgery by the traditional technique.

\section{Patients and Methods}

\section{Patient population}

From January 2000 to December 2008, 388 patients who had been submitted to coronary by pass surgery in our or other institutions underwent repeat coronary angiography at the Policlinico di Monza department of cardiac surgery. In 239 patients (62\%) CABG had been performed in other units by the "standard" technique while in the 149 patients operated by our team (38\%) revascularisation had been completed with the microsurgical approach. The need for readmission and repeat coronary angiography was dictated by a variety of cardiovascular conditions such as recurrence of angina, valvular disease, thoracic or abdominal aneurysms, and critical peripheral artery disease. In the two groups, the percent incidence of clinical conditions dictating readmission and cardiovascular surgery were similar (Table 1). Accordingly, there were no significant differences between the two groups, as regards age, sex, risk factors, previous MI, number of grafted vessels, type of conduits used and time elapsed from the initial operation (Table 2).

Table 1:

\begin{tabular}{|c|c|c|c|}
\hline Condition & Standard & Microsurgery & P value \\
\hline Ischemic HD & $76(32 \%)$ & $42(29 \%)$ & ns \\
\hline Valvular Disease & $91(38 \%)$ & $54(36 \%)$ & ns \\
\hline Aneurysms & $40(17 \%)$ & $31(20 \%)$ & ns \\
\hline $\begin{array}{c}\text { Peripheral } \\
\text { artery disease }\end{array}$ & $31(13 \%)$ & $22(15 \%)$ & ns \\
\hline
\end{tabular}

Table 2:

\begin{tabular}{|c|c|c|c|}
\hline & $\begin{array}{c}\text { Standard Surgery } \\
\text { n 239 (62\%) }\end{array}$ & $\begin{array}{c}\text { Microsurgery } \\
\text { n 149(38\%) }\end{array}$ & P value \\
\hline Age(years) & $63 \pm 16$ & $61 \pm 19$ & ns \\
\hline Female sex & $46(19)$ & $22(14)$ & ns \\
\hline Diabetes & $85(36 \%)$ & $48(32)$ & ns \\
\hline Hypertension & $129(53)$ & $85(57)$ & ns \\
\hline Previous MI & $111(46)$ & $64(42)$ & ns \\
\hline Hypercholesterolemia & $137(57)$ & $90(60)$ & ns \\
\hline Redo CABG & $23(9.6)$ & $15(10)$ & ns \\
\hline Years from surgery & $6.7 \pm 5.1$ & $5.8 \pm 4.3$ & ns \\
\hline N grafts & 666 & 354 & - \\
\hline N of grafts/pt. & $2.7 \pm ? ?$ & $2.3 \pm ? ?$ & ns \\
\hline LIMA & $197(29)$ & $130(35)$ & ns \\
\hline RIMA & $24(3.6)$ & $12(8)$ & ns \\
\hline Radial artery & $6(1)$ & 0 & ns \\
\hline Saphenous vein & $439(65)$ & $212(58)$ & ns \\
\hline
\end{tabular}

\section{Surgical technique}

Since 1990 all patients undergoing coronary by pass surgery in the department of cardiovascular surgery of the Policlinico di Monza are operated with a microsurgical technique. In the initial phase of implementation, we employed surgical loupes enabling a 6x magnification factor: subsequently, we used the Leica M500 frontal operating microscope which allows up to $8 \mathrm{x}$ magnifications (Figure 1). Compared to the traditional technique, high power magnification considerably reduces the amount of vessel wall involved in the suture and minimizes the distance between stitches. In fact, in agreement with the approach initially proposed by Carrel (Figure 2), the standard technique applies a continuous 7-8 zero suture and ...... gauge needles, with 3 stitches positioned at the two extremes and approximately 4 other stitches applied to the lateral aspects of the anastomosis Conversely, our approach employs a 8 zero continuous suture and a smaller needle (gauge). The amount of vessel wall involved in the suture and the distance between two adjacent stitches is no more than $0.5 \mathrm{~mm}$ and the total number of stitches applied for each anastomosis varies from 30 to 40 (Figure 3). The average time required to perform a microsurgical anastomosis is approximately 15 minutes.

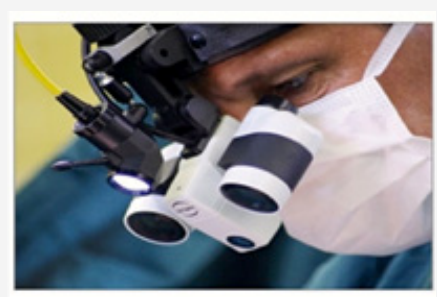

Figure 1

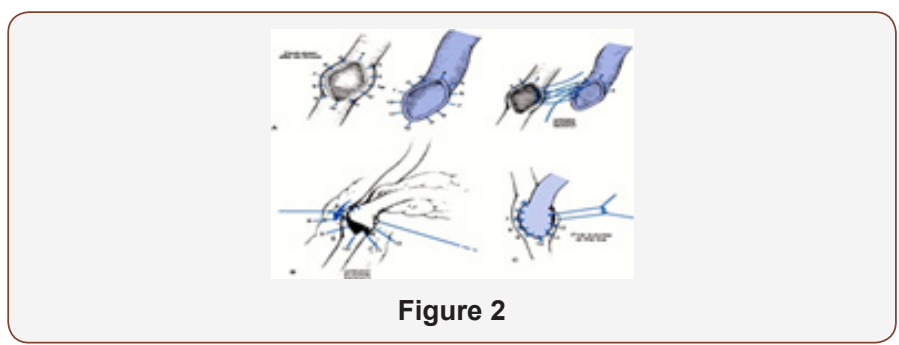




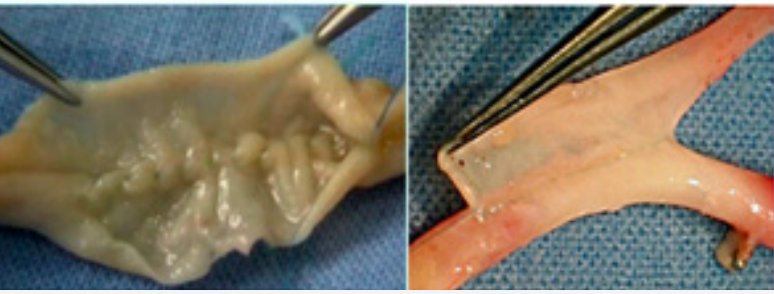

Figure 3

\section{Coronary angiography}

As already pointed out, the need for repeat coronary arteriography was dictated by the development of a variety of clinical situations that occurred after the initial by-pass operation. In the two groups, the time elapsed from surgery to the second admission was respectively $6.7 \pm 5$ and $5.8 \pm 4$ years (ns). In all study patients the investigation was carried out by the standard Judkins technique, using either the femoral or radial approach, as appropriate. For each coronary artery and grafts several projections, including cranio-caudal angulations were performed, in order to visualize the full length of graft and recipient vessel and to optimize visualization of the site of the anastomosis.

Coronary angiograms were analyzed in blind by two independent observers unaware of patients' identity and type of operation they had received. Graft patency was established when both the graft and the native vessel were fully opacified and contrast run-off occurred with a grade 3 TIMI flow (Figure 4).

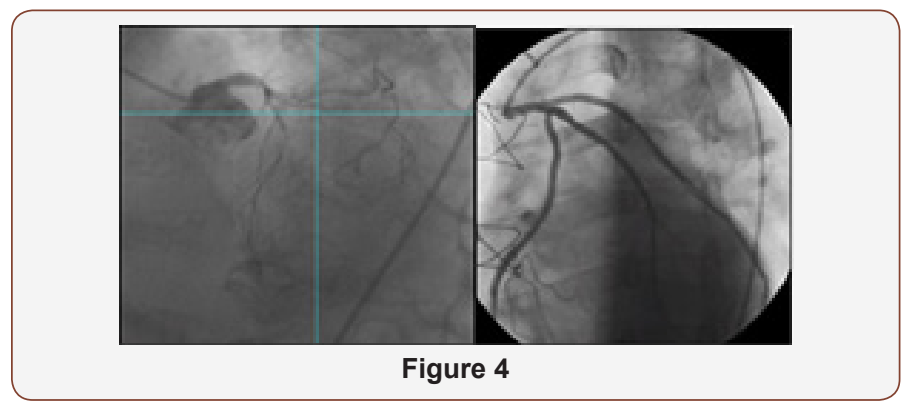

\section{Statistical analysis}

Differences in continuous variables were analyzed by the unpaired $\mathrm{T}$ test and Wilcoxon rank-sum test respectively for normally and non-normally distributed data. Categorical variables were analyzed by the chi-square test.

\section{Ethical aspects}

The study was approved by the Institutional Committee for Scientific Investigations. Patients gave oral informed consent to the use of clinical data pertaining this investigation. Hospital files were analyzed after having been made anonymous.

\section{Result}

The angiographic results are summarized in Table 3. Respectively 346 (52\%) of the 666 grafts performed with the "standard" technique and 297 of the 354 (83\%) grafts performed by microsurgery were patent. Regardless of the conduit used, patency rates were invariably greater when microsurgery had been employed. However, due to the relatively limited size of the study population, the difference between the to techniques reached statistical significance only when vein grafts were compared. Of the 651 venous conduits analyzed by angiography, 439 belonged to the group of patients operated in the standard fashion, while 212 were part of the microsurgery group. Of these grafts, respectively 168 $(38 \%)$ and $171(81 \%)$ were patent $(\mathrm{p}<0.005)$ (Figure 5 \& Table 3$)$.

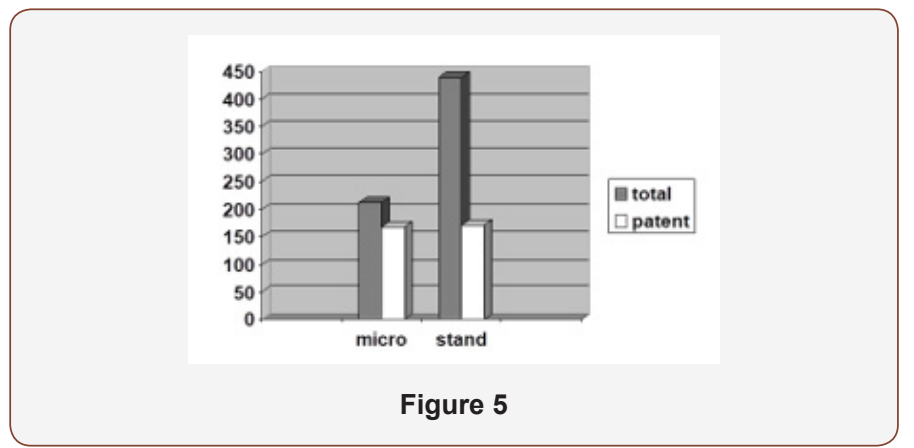

Table 3:

\begin{tabular}{|c|c|c|c|c|c|}
\hline \multirow{2}{*}{$\begin{array}{l}\text { Conduit } \\
\text { Type }\end{array}$} & \multicolumn{2}{|c|}{ Standard } & \multicolumn{2}{|c|}{ Microsurgery } & \multirow{2}{*}{ P Value } \\
\hline & $\begin{array}{l}\text { Total } \\
\text { Grafts }\end{array}$ & $\begin{array}{c}\text { Patent } \\
(\%)\end{array}$ & $\begin{array}{c}\text { Total } \\
\text { Grafts }\end{array}$ & $\begin{array}{c}\text { Patent } \\
(\%)\end{array}$ & \\
\hline LITA & 197 & $161(81 \%)$ & 130 & $117(90 \%)$ & 0.3 \\
\hline RITA & 24 & $14(58 \%)$ & 12 & $9(75 \%)$ & 0.48 \\
\hline $\begin{array}{c}\text { Saphenous } \\
\text { vein }\end{array}$ & 439 & $168(38 \%)$ & 212 & $171(81 \%)$ & $<0.005$ \\
\hline $\begin{array}{l}\text { Radial } \\
\text { artery }\end{array}$ & 6 & $3(50 \%)$ & & & - \\
\hline
\end{tabular}

\section{Discussion}

\section{Graft patency rates: traditional technique vs. microsurgery}

The results of our study show that the use of microsurgery results in greater patency rates for all conduits employed for revascularisation and that the difference is particularly significant for vein grafts.

Although arterial revascularization is currently recommended and represents the technique of choice for the left anterior descending coronary artery, vein grafts remain the most commonly used conduits for all other arteries [8]. As stated by Sabik, "there are several reasons for this. First, because of their relatively large diameter and wall characteristics saphenous veins are easy to use; second, they provide plenty of vascular material and can therefore be used to perform multiple grafts; third, the saphenous vein is long and can reach virtually any coronary artery; fourth, it easy to harvest" [8]. Nevertheless, common clinical experience indicates that venous conduits invariably exhibit lower patency rates than arterial grafts and suggests that improvement in surgical techniques should be sought, in order to improve long term performance of these conduits [9].

As already pointed out in the introductory session of this article, it is common belief that veins occlude earlier and more frequently than arteries, essentially because of hydrodynamic and biological factors. Indeed, being larger than arteries, they tend to 
produce slower flow rates, especially when a large caliber mismatch between graft and recipient vessel is present. Also, being endowed with a thinner wall and muscular media, they are poorly equipped to sustain the increased pressure and shear forces typical of the arterial circulation and tend to rapidly degenerate and to develop graft disease [10]. Even acknowledging the importance of these factors, the presence of significant stenosis at the site of the distal anastomosis is recognized to play a relevant role in graft failure, especially when the recipient vessel is small. Indeed, the rate of graft occlusion appears to be inversely related to the size of the grafted vessel [11] and the 10-year patency rate of vein grafts applied to the LAD was $90 \%$ if the vessel calibre was $2 \mathrm{~mm}$ or greater and $52 \%$ when LAD diameter was less than $2 \mathrm{~mm}$ [12].

\section{"Surgical" stenosis as a cause of coronary graft occlusion}

"Surgical" stenoses most commonly occur at the distal (coronary) end and surgical skill is an important factor in determining the fate of the graft. According to Poiseuille's law, blood flow varies as a function of the fourth power of vessel diameter and even small changes in diameter due to technical inaccuracy, may affect flow rates in a major way.

Among the factors potentially determining surgical stenoses, the thickness of vessel wall involved in the suture and the distance between stitches appear very important [9]. In fact, the more the thickness of vessel wall involved in the suture, the more the shortening of suture edges; the more the distance between two adjacent stitches, the more the reduction of vessel lumen (Figure $3)$.

In a morphologic investigation of occlusive changes of 95 coronary anastomoses, Griffith et al. [11] found that stitches applied at 0.5 and $1.0 \mathrm{~mm}$ from the edge of vessels measuring $2 \mathrm{~mm}$ in diameter cause respectively a 29 and $54 \%$ reduction in cross-sectional area. When applied to vessels of $1 \mathrm{~mm}$, the reduction in cross-section is 52 and $90 \%$. The critical areas of a coronary anastomosis are the toe and the heel. An insufficient number of stitches in these two areas may cause constriction and lead to early or late stenosis. Furthermore, a running suture exerts a purse-string effect, that may be prevented by applying many small bites (15 to 20) that also serve to prevent stenosis of the inflow or outflow coronary artery [13] (Edmunds H. In: "Cardiac surgery in the adult) These observations led us to believe that the use of high magnification optical tools, as typically practised in microvascular surgery, by allowing the use of smaller sutures, closer stitches, and less vessel wall, should minimize the likelihood of causing surgical stenoses (Figure 3).

\section{History of microvascular surgery}

The advances in the techniques and technology that popularized microsurgery began in the early 1960s and the first report of a vascular intervention employing this technique for the repair of blood vessels, was described by Jules Jacobson in 1960. Using an operating microscope, he coupled vessels as small as $1.4 \mathrm{~mm}$ and coined the term "microsurgery" [14]. Based on his experience, Harold Kleinert and Mort Kasdan, hand surgeons at Louisville University, performed the first revascularization of a partial digital amputation in 1963 [15].
Contemporary reconstructive microsurgery was introduced by an american plastic surgeon, dr. Harry J. Buncke who, in 1964, reported a rabbit ear re-implantation, using a garage as operating theatre and home-made instruments [16]. This was the first report of successful microsurgical intervention using blood vessels one millimeter in size. In 1966, Buncke used microsurgery to transplant a primate's great toe to its hand [17]. During the late sixties and early 1970s, plastic surgeons ushered in many new microsurgical innovations that were previously unimaginable. The first human microsurgical transplantation of the big toe to thumb was performed in April 1968 by John Cobbett, in England [18-19]. In Australia Ian Taylor [20] developed new techniques to reconstruct head and neck cancer defects with living bone from the hip or the fibula. Although primarily developed and used by plastic surgeons, a number of surgical specialties now use microsurgical techniques.

In the early seventies, Green e Loop proposed the use of the operating microscope to perform coronary bypass surgery. The technique was soon abandoned by the majority of cardiac centres, mainly because of the longer times required to complete the anastomosis and because of the difficulties in adapting the microscope position when performing anastomoses on the lateral and posterior walls of the heart. Our experience seems to disprove such perplexities as, in fact, we were able to apply the technique virtually to all recipient vessels, regardless of their epicardial position. Furthermore, microsurgery appeared particularly valuable on small vessels where the use of high power magnification and extremely thin sutures and needles, allowed to apply interrupted stitches on arteries of $1 \mathrm{~mm}$ diameter. Finally, although performing a distal anastomosis by microsurgery implies a slightly longer time than that required when the traditional technique is used, the minor prolongation of ischemic times associated with this approach is easily compensated by adequate myocardial protection.

Finally, interrupted sutures have been held by some as the gold standard for coronary anastomoses [21] and Loop et al reported that this technique was associated with the best longterm of internal mammary patency rates [22]. They observed that interrupted suturing consistently produced minimal anastomosis deformities and concluded that interrupted sutures should be used when constructing anastomoses in small coronary arteries as shortening of a continuous suture may cause focal constriction. However, in spite of the theoretical superiority of the interrupted sutures, constructing anastomoses with continuous sutures has progressively gained popularity and has become standard practice in coronary surgery due to its advantages in terms of ease and operating speed.

\section{Conclusion}

Our results indicate that applying a microsurgical technique to coronary by pass surgery results in significantly greater patency rates. The technique appears particularly valuable when applied to vein grafts and to small recipient vessels.

\section{Study limitations}

Although the two study groups appear quite similar, as regards physical and clinical characteristics, our investigation is affected by 
the typical limitations of retrospective studies and by their potential selection biases. Furthermore, while all patients belonging to the microsurgery group were operated in the same institution and with the same technique, those constituting the control group were operated in different centres, possibly employing different technical approaches. This certainly represents a further limitation of our study, but the patency rates of vein grafts that we observed in the control group are quite similar to those reported in the current literature. This suggests that the results obtained in this population are representative of "real world" bypass surgery.

\section{Acknowledgement}

None.

\section{Conflict of Interest}

No conflict of interest.

\section{References}

1. Loop FD, Lytle BW, Cosgrove DM, Stewart RW, Goormastic M, et al (1986) Influence of the internal-mammary graft on 10-year survival and other cardiac events. N Engl J Med 314: 1-6.

2. Widimsky P, Straka Z, Stros P, Jirasek K, Dvorak J, et al. (2004) One-year coronary bypass graft patency: a randomized comparison between offpump and on-pump surgery angiographic results of the PRAGUE-4 trial. Circulation 110(22): 3418-3423.

3. Alexander JH, Hafley G, Harrington RA, Peterson ED, Ferguson TB, et al. (2005) Efficacy and safety of edifoligide, an E2F transcription factor decoy, for prevention of vein graft failure following coronary artery bypass graft surgery: PREVENT IV: a randomized controlled trial. PREVENT IV Investigators JAMA 294(19): 2446-2454

4. Tatoulis J, Buxton B, Fuller J (2004) Patency of 2127 arterial to coronary conduits over 15 years. Ann Thor Surg 77: 93-101.

5. Campeau L, Enjalbert M, Lespérance J, Vaislic C, Grondin CM, et al. (1983) Atherosclerosis and late closure of aortocoronary saphenous vein grafts: sequential angiographic studies at 2 weeks, 1 year, 5 to 7 years, and 10 to 12 years after surgery. Circulation 68 Suppl II: II1-II7.

6. Grondin CM, Campeau L, Lespérance J, Enjalbert M, Bourassa MG, et al. (1984) Comparison of late changes in internal mammary artery and saphenous vein grafts in two consecutive series of patients 10 years after operation. Circulation 70 Suppl I: I208-I212.

7. Goldman S, Zadina K, Moritz T, Ovitt T, Sethi G, et al. (2004) Long term patency rates of saphenous vein and internal mammary grafts after coronary by pass surgery. JACC 44: 2149-2156.
8. Sabik JF (2011) Understanding saphenous vein graft patency. Circulation 124: 273-275.

9. Hutchins GM, Bulkley BH (1977) Mechanisms of occlusion of saphenous vein--coronary artery jump grafts. J Thorac Cardiovasc Surg 73(5): 660667.

10. Shuhaiber JH, Evans AN, Massad MG, Geha AS (2002) Mechanisms and future directions for prevention of vein graft failure in coronary bypass surgery. Eur J Cardioth Surg 22: 387-396.

11. Griffith LS, Bulkley BH, Hutchins GM, Brawley RK (1977) Occlusive changes at the coronary artery--bypass graft anastomosis. Morphologic study of 95 grafts J Thorac Cardiovasc Surg 73(5): 668-679.

12. Goldman S, Zadina K, Moritz T, Ovitt T, Sethi G, et al. (2004) VA Cooperative Study Group Long-term patency of saphenous vein and left internal mammary artery grafts after coronary artery bypass surgery: results from a Department of Veterans Affairs Cooperative Study. J Am Coll Cardiol 44(11): 2149-2156.

13. Cohn Lawrence H, Edmunds LH (2003) Cardiac Surgery in the Adult. Mcgraw-hill Professional.

14. KLEINERT HE, KASDAN ML (1963) Restoration of Blood Flow in Upper Extremity Injuries. J Trauma 3(5): 461-476.

15. Buncke H, Schulz W (1966) Total ear reimplantation in the rabbit utilising microminiature vascular anastomoses. Br J Plast Surg 19(1): $15-22$

16. Buncke HJ, Buncke CM, Schulz WP (1966) Immediate Nicoladoni procedure in the Rhesus monkey, or hallux-to-hand transplantation, utilising microminiature vascular anastomoses. Br J Plast Surg 19(4): 332-337.

17. Dongyue Y, Yudong G (1979) Thumb reconstruction utilizing second toe transplantation by microvascular anastomosis: report of 78 cases. Chin Med J (Engl) 92(5): 295-309.

18. Cobbet JR (1969) TFree digital transfer. Report of a case of transfer of a great toe to replace an amputated thumb. J Bone Joint Surg Br 51(4): 677-679.

19. Taylor GI, Miller GD, Ham FJ (1975) The free vascularized bone graft. A clinical extension of microvascular techniques. Plast Reconstr Surg 55(5): 533-544.

20. Lytle BW, Loop FD, Cosgrove DM, Ratliff NB, Easley K, et al. (1990) Long-term (5-12 years) serial studies of internal mammary artery and saphenous vein coronary artery bypass grafts. J Thorac Cardiovasc Surg 15: $15-20$.

21. Loop FD, Lytle BW, Cosgrove DM, Stewart RW, Goormastic M, et al. (1986) Influence of the internal-mammary graft on 10-year survival and other cardiac events. N Engl J Med 314: 1-6. 